\title{
Nutritional habits and free grazing regimen of productive animals along with specific ingredients are influential factors for the antioxidant properties of milk: From farm to market
}

\author{
ARISTIDIS S. VESKOUKIS, EFTHALIA KERASIOTI, KONSTANTINOS SIDIROPOULOS, \\ ILEKTRA MARAGOU, ZOI SKAPERDA and DEMETRIOS KOURETAS \\ Department of Biochemistry and Biotechnology, University of Thessaly, 41500 Larissa, Greece
}

Received December 11, 2019; Accepted January 22, 2020

DOI: $10.3892 /$ br.2020.1301

\begin{abstract}
Milk is a fundamental product of animal origin for human health and well-being. It possesses crucial biological properties, which depend on its composition and production methodology. To this end, one of the aims of the present study was to assess the impact of the nutritional and dwelling patterns of productive animals on the antioxidant potency of their generated milk. Thus, samples of sheep milk were collected for 30 consecutive days during the spring months from 5 different farms with different traits and its antioxidant activity was measured. Furthermore, this study aimed to evaluate the antioxidant capacity of 15 commercially available milk samples of different animal origin (i.e., cow and buffalo) and type (i.e., full-fat, light and chocolate) derived from 5 different companies. For all the experiments, the assay that examines the ability of the milk samples to reduce the $\mathrm{DPPH}^{*}$ radical was used. It was thus found that the free-grazing regimen of the farm sheep dwelling at high altitude resulted in the production of milk with a greater antioxidant potential. On the other hand, it was also found that the samples of chocolate milk exhibited notably mote potent antioxidant activity than the full-fat and light samples, obviously due to the excessively high composition in antioxidant molecules present in cocoa. From this study that holistically examined the antioxidant properties of milk derived from three different productive animal species, it becomes evident that the nutritional and grazing practices, as well as specific ingredients (i.e., cocoa) lead to the generation of milk with high added biological value.
\end{abstract}

Correspondence to: Professor Demetrios Kouretas, Department of Biochemistry and Biotechnology, University of Thessaly, Viopolis, Mezourlo, 41500 Larissa, Greece

E-mail: dkouret@uth.gr

Key words: milk, antioxidant capacity, farm animals, market

\section{Introduction}

Milk is a food stuff with exceptional nutritional value and one of the few components of human nutrition that can be consumed without any further processing. Its history dates back to 9,000 B.C. and since then it is a necessary constituent of human and animal diet from infancy until the end of adult life (1). Milk has manifold uses, including the feeding of infants and partly the nourishment of children and adults, the presence in several processed foods (i.e., pastry products and candies) and in other milk-based goods, such as yoghurt and butter (2). Although obvious, defining milk is not a simple task. This is the reason for the existence of several definitions, and two of the most influential are hereby presented. The World Health Organization and the Food and Agriculture Organization of the United Nations defined it in the Codex Alimentarius in 2011 as 'the normal mammary secretion of milking animals obtained from one or more milkings without either addition to it or extraction from it, intended for consumption as liquid milk or for further processing' (3). Milk has also been defined by the prestigious and historic Merriam Webster Dictionary as 'a fluid secreted by the mammary glands of females for the nourishment of their young', 'milk from an animal and especially a cow used as food by people' and 'a food product produced from seeds or fruit that resembles and is used similarly to cow's milk'.

The composition of milk varies in terms of the mammal from which it originates, the animal breed, the lactation period, as well as the feeding, the dwelling and grazing conditions (4). When comparing sheep and cow milk, sheep milk contains fat in small globules, which are smaller than those of cow milk, whereas milk derived from sheep contains short-chain fatty acids in higher amounts (20-25\%) than cow milk (10-12\%) (4). Additionally, the protein content of sheep milk is $40 \%$ higher than that of cow milk, whereas the ratio of casein and whey protein are the same. As regards whey protein, sheep milk contains higher proportions of $\beta$-lactoglobulin and lower concentrations of serum albumin and immunoglobulin compared to cow milk (5). Furthermore, sheep milk is richer than cow milk in crucial minerals (i.e., calcium, potassium and phosphorus), as well as in vitamins and several antioxidant enzymes (5). Buffalo milk on the other hand is a product of 
Table I. Characteristics of the 5 farms (i.e., A, B, C, D and E) where the sheep milk samples were obtained from.

\begin{tabular}{ll}
\hline Farm & \multicolumn{1}{c}{ Characteristics } \\
\hline A & The animals were reared exclusively at stall $(<600 \mathrm{~m}$ of altitude) \\
& Fed with silage from corn, wheat and from by-products of olive oil industry \\
B & The animals were reared both at stall and in very restricted pasture area \\
& The nutritional value of the grass has been degraded due to over-pasture \\
C & The animals were reared both at stall and in a pasture area $(<600 \mathrm{~m}$ of altitude) \\
& Fed also with straw from wheat, barley, corn and from by-products of olive oil industry \\
D & The animals were reared in a free-grazing regimen \\
& Grazing in pasture both at $600-800 \mathrm{~m}$ and $>1,700 \mathrm{~m}$ of altitude \\
E & The animals were reared exclusively at stall \\
& Fed with silage from corn, barley, rye and soy were used
\end{tabular}

high nutritive value due to its constituents, but also due to its chemical and physical traits, although relevant experimental evidence is limited (6). Buffalo milk contains higher amounts of fat than cow milk $(6.5-8.5 \%)$ and it is also more beneficial to human health due to its high concentration of minerals and antioxidant enzymes (6). In general, however, the constituents of milk, namely whey protein, casein, lactoferrin, carotenoids, tocopherols and ascorbate along with glutathione peroxidase and other enzymes, exert potent antioxidant effects. It has been demonstrated that these constituents prevent the lipid oxidation of milk, thus reassuring its high quality (7). Apart from the antioxidant potential of milk components, it has also been reported that the oral administration of lactoferrin is a positive treatment against psychological stress in humans (8). In addition, casein has been shown to induce the proliferation of bone marrow mononuclear cells and to increase survival in a mouse model of leukemia (9).

As stated above, the quality and nutritional value of milk are inextricably linked to the grazing and development conditions of the productive animals (10). Milk fat is the constituent that is affected the most by the aforementioned factors followed by proteins and carbohydrates (1). The impaired milk quality is partly the outcome of the disruption of the equilibrium between oxidative and antioxidant processes in the productive animals and in the product per se. Fatty acid composition is affected by the aforementioned disruption and leads to milk with low antioxidant potential (11). It has been reported that free grazing animals are more efficient in milk production than others that are fed both in stalls and in unrestricted areas (12). Free grazing is a fundamental factor that affects the nutritional and antioxidant profile of sheep milk along with the feeding habits of the animals (13).

On the basis of the above, it has become evident that the antioxidant capacity of milk samples available in the market is dependent on their constituents and the productive animal species. However, if one focuses on a previous stage of milk production, namely its secretion and collection from the respective animal, other factors, such as the grazing regimen, the altitude of the areas where the animals live and the feed are decisive as regards its antioxidant potential. The scope of this study, hence, was to investigate the putative antioxidant properties of sheep milk samples obtained from 5 farms with different characteristics in order to associate them with parameters, such as the grazing regimen and the feeding profile. In addition, the antioxidant potential of several full-fat, light and chocolate milk samples derived from cows and buffalo dwelling in different prefectures of Central and Northern Greece were examined in order to evaluate the role of the extra components added in the milk that is found in the market on its antioxidant action.

\section{Materials and methods}

Collection of milk samples from Greek farms. Five farms located in the region of Western Thessaly (Trikala), Greece were selected for the sample collection. These farms differed in the following factors: The place where the animals (i.e., sheep) dwell, namely totally or partly free or totally or partly at stall, the feeding regimen (i.e., free grazing, commercial feed or both) and their altitude. These characteristics are described in detail in Table I. Milk samples $(50 \mathrm{ml})$ were collected for 30 consecutive days during the spring months from each farm and were transferred on ice to the laboratory for analysis.

Collection of milk samples from the Greek market. Milk samples with different geographical origin were collected from the Greek market. These samples were full-fat, light and chocolate milk from cows and buffalo which originated from Eastern Thessaly (Volos), Central Macedonia (Thessaloniki), Eastern Macedonia (Serres), Eastern Macedonia (Drama) and Central Macedonia (Thessaloniki). Immediately following their purchase, they were transferred to the laboratory for analysis.

$D_{P P H^{\bullet}}$ radical scavenging assay. This assay was based on the ability of the milk samples to reduce the commercially available $\mathrm{DPPH}^{\bullet}$ radical, as previously described $(14,15)$. The reaction mixture contained the $\mathrm{DPPH}^{*}$ radical solution prepared on the day of the experiment dissolved in methanol and the milk samples in a wide range of volumes expressed in $\mu \mathrm{l}$. The reaction samples were mixed, incubated in the dark at room temperature for $20 \mathrm{~min}$ and their absorbance was monitored at $517 \mathrm{~nm}$ using a HITACHI U-1500 spectrophotometer supplied by Analytical Instruments SA. The tested sample alone was used as the blank and the $\mathrm{DPPH}^{\circ}$ radical 
Table II. The mean scavenging capacity of the sheep milk samples obtained from 5 different farms of Western Thessaly (Trikala) assessed via their ability to scavenge $\mathrm{DPPH}^{\bullet}$ expressed as the $\mu \mathrm{l}$ of the samples at the $\mathrm{IC}_{50}$ value.

Mean $\mathrm{DPPH}^{\bullet}$ scavenging capacity after 30 consecutive days of sampling Farm ( $\mu$ l of the sample at $\left.\mathrm{IC}_{50} \pm \mathrm{SD}\right)$

\begin{tabular}{ll}
\hline A & $159 \pm 7^{\mathrm{a}}$ \\
B & $125 \pm 4^{\mathrm{a}}$ \\
C & $143 \pm 6^{\mathrm{a}}$ \\
D & $105 \pm 3$ \\
E & $112 \pm 4^{\mathrm{a}}$
\end{tabular}

a Statistically significant compared to the samples from farm D. SD, standard deviation.

with methanol was the control. The antioxidant activity of the samples was calculated on the basis of the percentage reduction of the $\mathrm{DPPH}^{\bullet}$ radical compared to the control. The volume of each sample that reduced the $\mathrm{DPPH}^{*}$ radical at $50 \%$ was considered as the $\mathrm{IC}_{50}$ value.

Statistical analysis. The data were analyzed with one-way ANOVA followed by Dunnett's test using the statistical package for social sciences (SPSS, Inc., version 21.0). All results are expressed as the means \pm standard deviation (SD). The level of the statistical significance was set at $\mathrm{P}<0.05$.

\section{Results}

Antioxidant properties of the milk samples obtained from the 5 different farms. The range of the mean $\mathrm{DPPH}^{\bullet}$ scavenging capacity of the milk samples following 30 consecutive days of sampling ranged between 105 and $159 \mu \mathrm{l}$ at $\mathrm{IC}_{50}$ (Table II). The samples from farm $\mathrm{D}$ were the most potent since they exhibited statistically significantly lower $\mathrm{IC}_{50}$ values from the samples of the remaining 4 farms $(\mathrm{P}<0.05)$.

Antioxidant properties of the milk samples that are available on the market. The DPPH ${ }^{\bullet}$ scavenging capacity of the full-fat milk samples (both cow and buffalo) ranged between 110 and $200 \mu \mathrm{l}$ at $\mathrm{IC}_{50}$, the capacity of the light samples ranged between 155 and $200 \mu \mathrm{l}$ at $\mathrm{IC}_{50}$, whereas in the chocolate milk samples, it was measured between 4 and $5 \mu 1$ at $\mathrm{IC}_{50}$ (Table III). A statistically significant difference was observed in the mean $\mathrm{IC}_{50}$ values of the chocolate milk compared to those of the full-fat and the light samples $(\mathrm{P}<0.05)$. No significant differences were observed between the full-fat and light samples, whereas no distinct differences were observed on the basis of the geographical origin of the samples.

\section{Discussion}

The present study examined the antioxidant properties of several full-fat, light and chocolate milk samples derived from cow and buffalo and originating from different regions of Central and Northern Greece. The results revealed that the samples of chocolate milk exerted a greater scavenging capacity against $\mathrm{DPPH}^{\bullet}$ radical compared to the other tested

Table III. The characteristics and the scavenging capacity of the tested milk samples assessed via their ability to scavenge DPPH expressed as the $\mu \mathrm{l}$ of the samples at the $\mathrm{IC}_{50}$ value.
Type
Animal origin
Geographical origin

$\mathrm{DPPH}^{\bullet}$ scavenging capacity

Full-fat

Cow

Buffalo

Light

Cow

Buffalo

Chocolate

Cow

Buffalo

Eastern Thessaly (Volos)
Central Macedonia (Thessaloniki)
Eastern Macedonia (Serres)
Eastern Macedonia (Drama)
Central Macedonia (Thessaloniki)
Mean value

Eastern Thessaly (Volos)

Central Macedonia (Thessaloniki)

Eastern Macedonia (Serres)

Eastern Macedonia (Drama)

Central Macedonia (Thessaloniki)

Mean value

Eastern Thessaly (Volos)

Central Macedonia (Thessaloniki)

Eastern Macedonia (Serres)

Eastern Macedonia (Drama)

Central Macedonia (Thessaloniki)

Mean value $(\mu 1$ of the sample at IC $50 \pm$ SD)
$167 \pm 3$
$200 \pm 3$
$200 \pm 8$
$110 \pm 3$
$200 \pm 11$
$175 \pm 39^{a}$
$155 \pm 4$
$182 \pm 3$
$195 \pm 10$
$200 \pm 5$
$200 \pm 10$
$186 \pm 19^{a}$
$4.3 \pm 0.6$
$5 \pm 0.7$
$4 \pm 0.6$
$4 \pm 0.3$
$4 \pm 0.6$
$4.3 \pm 0.4$ 
samples. The geographical origin of the milk did not seem to play a key role in its antioxidant activity. Furthermore, samples of sheep milk from 5 farms with different characteristics were collected for 30 days and their antiradical activity against $\mathrm{DPPH}^{\bullet}$ was examined. The milk samples originating from farm $D$, which was the only farm where the animals were fed in a free-grazing regimen at high altitude, exhibited the most potent antioxidant activity.

The antioxidant activity of the tested milk samples was assessed through the assay involving their ability to reduce the commercially available DPPH ${ }^{\bullet}$ radical. This biomarker is widely used in studies that intend to evaluate the antioxidant activity of differential compounds, such as plant (15-17), plant-derived products such as coffee beans (18), as well as animal feeds in the form of silage (19-21). Furthermore, the $\mathrm{DPPH}^{\bullet}$ radical is also the central molecule for the assay that evaluates the total antioxidant capacity of human and experimental animal blood and tissues after redox-altering stimuli, namely exercise (22-24), nutritional interventions $(25,26)$ and toxicological treatments $(27)$. Therefore, it appears that this is a reliable assay providing useful results in a wide range of experimental approaches $(28,29)$.

Milk is a fundamental food for human health as is the case for the products that are derived from it (11). The antioxidant properties of the constituents of milk are one of the reasons for its high nutritional value. Specifically, it has been demonstrated that the caseins of milk exert potent antioxidant effects $(30,31)$. Whey protein is also present in milk and its strong antioxidant activity has been described as well (32-34). Apart from its native compounds, milk products that are available for the consumers may have been enriched with other ingredients that enhance its antioxidant action. One of these is cocoa whose antioxidant properties have been extensively described (35). Taking into consideration that the chocolate milk samples tested herein exhibited an exceptionally higher ability to reduce $\mathrm{DPPH}^{\bullet}$ radical, it can be implied that cocoa is the constituent that intensifies these samples against putative oxidative modifications of milk. It is worth mentioning that this is the only factor discriminating the herein measured samples whereas geographical or animal origin were not effective.

As regards the results obtained from the milk samples originating from the 5 different farms of the Western Thessaly region, the ones that exhibited the most potent antioxidant activity were derived from farm D. This was the only farm that was substantially different compared to the other 4 farms. Notably, the animals of farm D were reared in a free-grazing regimen. Additionally, the grazing of the animals took place in areas of high altitude, between 600 and $800 \mathrm{~m}$ and also $>1,700 \mathrm{~m}$ in particular. These two parameters are crucial for the exceptional antioxidant activity of the derived milk. To this end, it has been found that the grazing pasture contains higher amounts of polyunsaturated fatty acids, lower saturated fatty acids and the generated milk is of higher nutritional value compared to milk derived from animals fed exclusively at stall $(13,36)$. In line with the above-mentioned studies and with the results reported in this study, the diversity of the pasture with which free-grazing animal are fed contains numerous nutritious compounds that are absent from the grass present at stalls (37).

It is important to highlight that the antioxidant properties of the milk samples derived from the 5 farms that were examined herein are crucial regarding the generation of sheep milk feta cheese. Feta cheese is a traditional Greek product with protective designation of origin (PDO) that possesses marked characteristics, such as the salty taste and texture. These traits are unique; therefore, feta-like cheeses produced in countries other than Greece cannot be compared with the original product. Factors, such as the animal species, the soil and the climate of the region in which feta is produced give to this cheese an exceptional character among all Greek products (38). The antioxidant activity of feta cheese is decisive in order to acquire a product with high additive value and quality (39). To this end, in the present study, it is proposed that the investigation of the antiradical properties of sheep milk samples, obtained from farms during the spring months, against $\mathrm{DPPH}^{\bullet}$ and other similar radicals can be a solid base for a producer in order to generate feta cheese with superior quality and probably low cost for him and the consumers.

In conclusion, there is limited evidence in the literature concerning the role of the grazing regimen and the feeding practice of productive animals (i.e., sheep) on the antioxidant activity of the generated milk. Furthermore, to the best of our knowledge, there is currently no available evaluation of the most frequently consumed cow and buffalo milk samples in the Greek market in terms of their antioxidant properties associated with their major constituents. It was thus concluded that free grazing at a high altitude is a decisive factor for the production of milk with potent antioxidant activity and a high nutritional value. Furthermore, the chocolate milks found in the market are far more potent antioxidants compared to the full-fat and light ones, evidently due to their high content in cocoa, regardless of the geographical or animal origin. This holistic approach from farm to market is anticipated to provide new insight into the conditions of the development of the productive animals in farms and the composition of milks present in the Greek market.

\section{Acknowledgements}

Not applicable.

\section{Funding}

The present study was funded by the post-graduate programs 'Toxicology' and 'Biotechnology-Quality Assessment in Nutrition and the Environment' in the Department of Biochemistry and Biotechnology at the University of Thessaly.

\section{Availability of data and materials}

All data generated or analyzed during this study are included in this published article or are available from the corresponding author on reasonable request.

\section{Authors' contributions}

DK conceived and designed the study. ASV, EK and DK were responsible for the interpretation of the results, and for drafting 
and finalizing the manuscript. KS, IM and ZS performed the experiments and were involved in data analysis. All authors read and approved the final manuscript.

\section{Ethics approval and consent to participate}

Not applicable.

\section{Patient consent for publication}

Not applicable.

\section{Competing interests}

The authors declare that they have no competing interests.

\section{References}

1. Kailasapathy K: Chemical Composition, Physical, and Functional Properties of Milk and Milk Ingredients. In: Dairy Processing and Quality Assurance. Chandan RC, Kilara A and Shah NP (eds). Wiley-Blackwell, Oxford, 2015.

2. Fox PF and McSweeney PLH: Dairy Chemistry and Biochemistry. Blackie Academic and Professional, New York, NY, 1998.

3. Codex Alimentarius: Codex general standard for the use of dairy terms (CODEX STAN 206-1999). Joint FAO/WHO food standard programme. FAO, Rome, 1999.

4. Wendorff WL: Sheep milk and milk products: composition. In: Encyclopedia of animal science. Pond WG and Bell AW (eds). Marcel Dekker, New York, NY, 2005.

5. Balthazar CF, Pimentel TC, Ferrão LL, Almada CN, Santillo A, Albenzio M, Mollakhalili N, Mortazavian AM, Nascimento JS Silva MC, et al: Sheep Milk: Physicochemical Characteristics and Relevance for Functional Food Development. Compr Rey Food Sci Food Saf 16: 247-262, 2017

6. Ménard O, Ahmad S, Rousseau F, Briard-Bion V, Gaucheron F and Lopez C: Buffalo vs. cow milk fat globules: Size distribution, zeta-potential, compositions in total fatty acids and in polar lipids from the milk fat globule membrane. Food Chem 120: 544-551, 2010.

7. Revilla I, González-Martín MI, Vivar-Quintana AM, Blanco-López MA, Lobos-Ortega IA and Hernández-Hierro JM Antioxidant capacity of different cheeses: Affecting factors and prediction by near infrared spectroscopy. J Dairy Sci 99: 5074-5082, 2016.

8. Shinjo T, Sakuraba K, Nakaniida A, Ishibashi T, Kobayashi M, Aono Y and Suzuki Y: Oral lactoferrin influences psychological stress in humans: A single-dose administration crossover study. Biomed Rep 8: 426-432, 2018.

9. Ledesma-Martínez E, Pérez-Cordero C, Córdova-Galaviz Y, Sánchez-Tellez G, Huerta-Yepez S, Aguiñiga-Sánchez I, Miranda-Peralta E, Monroy-García A, Weiss-Steider B and Santiago-Osorio E: Casein induces the proliferation of bone marrow mononuclear cells, apoptosis of WEHI-3 leukaemic cells and increased survival in a leukaemia mouse model. Oncol Lett 4: 461-466, 2012.

10. Skaperda Z, Veskoukis AS and Kouretas D: Farm animal welfare, productivity and meat quality: Interrelation with redox status regulation and antioxidant supplementation as a nutritional intervention (Review). World Acad Sci J 1: 177-183, 2019.

11. Khan IT, Nadeem M, Imran M, Ullah R, Ajmal $M$ and Jaspal MH: Antioxidant properties of Milk and dairy products: A comprehensive review of the current knowledge. Lipids Health Dis 18: 41, 2019.

12. Mohammed R, Stanton CS, Kennelly JJ, Kramer JK, Mee JF, Glimm DR, O'Donovan M and Murphy JJ: Grazing cows are more efficient than zero-grazed and grass silage-fed cows in milk rumenic acid production. J Dairy Sci 92: 3874-3893, 2009.

13. Cabiddu A, Decandia M, Addis M, Piredda G, Parisi A and Molle G: Managing Mediterranean pastures in order to enhance the level of beneficial fatty acids in sheep milk. Small Rumin Res 59: 169-180, 2005.
14. Brand-Williams W, Cuvelier ME and Berset C: Use of a free radical method to evaluate antioxidant activity. Lebensm Wiss Technol 28: 25-30, 1995.

15. Veskoukis AS, Kyparos A, Nikolaidis MG, Stagos D, Aligiannis N, Halabalaki M, Chronis K, Goutzourelas N, Skaltsounis L and Kouretas D: The antioxidant effects of a polyphenol-rich grape pomace extract in vitro do not correspond in vivo using exercise as an oxidant stimulus. Oxid Med Cell Longev 2012: 185867, 2012.

16. Spanou C, Stagos D, Tousias L, Angelis A, Aligiannis N, Skaltsounis AL and Kouretas D: Assessment of antioxidant activity of extracts from unique Greek varieties of Leguminosae plants using in vitro assays. Anticancer Res 27 (5A): 3403-3410, 2007.

17. Kouka P, Tekos F, Valta K, Mavros P, Veskoukis AS, Angelis A, Skaltsounis AL and Kouretas D: Olive tree blossom polyphenolic extracts exert antioxidant and antimutagenic activities in vitro and in various cell lines. Oncol Rep 42: 2814-2825, 2019.

18. Priftis A, Stagos D, Konstantinopoulos K, Tsitsimpikou C, Spandidos DA, Tsatsakis AM, Tzatzarakis MN and Kouretas D: Comparison of antioxidant activity between green and roasted coffee beans using molecular methods. Mol Med Rep 12: 7293-7302, 2015.

19. Makri S, Kafantaris I, Stagos D, Chamokeridou T, Petrotos K, Gerasopoulos K, Mpesios A, Goutzourelas N, Kokkas S, Goulas P, et al: Novel feed including bioactive compounds from winery wastes improved broilers' redox status in blood and tissues of vital organs. Food Chem Toxicol 102: 24-31, 2017.

20. Makri S, Kafantaris I, Savva S, Ntanou P, Stagos D, Argyroulis I, Kotsampasi B, Christodoulou V, Gerasopoulos K, Petrotos K, et al: Novel Feed Including Olive Oil Mill Wastewater Bioactive Compounds Enhanced the Redox Status of Lambs. In Vivo 32: 291-302, 2018.

21. Kafantaris I, Stagos D, Kotsampasi B, Hatzis A, Kypriotakis A, Gerasopoulos K, Makri S, Goutzourelas N, Mitsagga C, Giavasis I, et al: Grape pomace improves performance, antioxidant status, fecal microbiota and meat quality of piglets. Animal 12: 246-255, 2018.

22. Veskoukis AS, Nikolaidis MG, Kyparos A, Kokkinos D, Nepka C, Barbanis S and Kouretas D: Effects of xanthine oxidase inhibition on oxidative stress and swimming performance in rats. Appl Physiol Nutr Metab 33: 1140-1154, 2008.

23. Veskoukis AS, Nikolaidis MG, Kyparos A and Kouretas D: Blood reflects tissue oxidative stress depending on biomarker and tissue studied. Free Radic Biol Med 47: 1371-1374, 2009.

24. Spanidis Y, Veskoukis AS, Papanikolaou C, Stagos D, Priftis A, Deli CK, Jamurtas AZ and Kouretas D: Exercise-Induced Reductive Stress Is a Protective Mechanism against Oxidative Stress in Peripheral Blood Mononuclear Cells. Oxid Med Cell Longev 2018: 3053704, 2018.

25. Veskoukis AS, Goutianos G, Paschalis V, Margaritelis NV, Tzioura A, Dipla K, Zafeiridis A, Vrabas IS, Kyparos A and Nikolaidis MG: The rat closely mimics oxidative stress and inflammation in humans after exercise but not after exercise combined with vitamin C administration. Eur J Appl Physiol 116: 791-804, 2016

26. Priftis A, Soursou V, Makiou AS, Tekos F, Veskoukis AS, Tsantarliotou MP, Taitzoglou IA and Kouretas D: A lightly roasted coffee extract improves blood and tissue redox status in rats through enhancement of GSH biosynthesis. Food Chem Toxicol 125: 305-312, 2019

27. Fountoucidou P, Veskoukis AS, Kerasioti E, Docea AO, Taitzoglou IA, Liesivuori J, Tsatsakis A and Kouretas D: A mixture of routinely encountered xenobiotics induces both redox adaptations and perturbations in blood and tissues of rats after a long-term low-dose exposure regimen: The time and dose issue. Toxicol Lett 317: 24-44, 2019.

28. Veskoukis A, Kerasioti E, Priftis A, Kouka P, Spanidis Y, Makri S and Kouretas D: A battery of translational biomarkers for the assessment of the in vitro and in vivo antioxidant action of plant polyphenolic compounds: The biomarker issue. Curr Opin Toxicol 13: 99-109, 2019.

29. Olszowy M and Dawidowicz AL: Is it possible to use the DPPH and ABTS methods for reliable estimation of antioxidant power of colored compounds? Chem Pap 72: 393-400, 2018.

30. Rival SG, Fornaroli S, Boeriu CG and Wichers HJ: Caseins and casein hydrolysates. 1. Lipoxygenase inhibitory properties. J Agric Food Chem 49: 287-294, 2001

31. Kitts DD: Antioxidant properties of casein phosphopeptides. Trends Food Sci Technol 16: 549-554, 2005. 
32. Kerasioti E, Stagos D, Priftis A, Aivazidis S, Tsatsakis AM, Hayes AW and Kouretas D: Antioxidant effects of whey protein on muscle C2C12 cells. Food Chem 155: 271-278, 2014.

33. Kerasioti E, Veskoukis A, Virgiliou C, Theodoridis G, Taitzoglou I and Kouretas D: The Strong Antioxidant Sheep/Goat Whey Protein Protects Against mTOR Overactivation in Rats: A Mode of Action Mimicking Fasting. Antioxidants 8: E71, 2019.

34. Tong LM, Sasaki S, McClements DJ and Decker EA: Antioxidant activity of whey in a salmon oil emulsion. J Food Sci 8: 1325-1329, 2001.

35. Katz DL, Doughty K and Ali A: Cocoa and chocolate in human health and disease. Antioxid Redox Signal 15: 2779-2811, 2011.

36. D'Urso S, Cutrignelli MI, Calabrò S, Bovera F, Tudisco R, Piccolo V and Infascelli F: Influence of pasture on fatty acid profile of goat milk. J Anim Physiol Anim Nutr (Berl) 92: 405-410, 2008.
37. Martin N, Verdier-Metz I, Buchin S, Hurtaud C and Coulon JB: How do the nature of forages and pasture diversity influence the sensory quality of dairy livestock products? Anim Sci 81: 205-212, 2005 .

38. Kasapis S and Boskou D: Rheological and sensory properties of popular greek foodstuffs: A review. Int J Food Prop 4: 327-340, 2001.

39. Cervato G, Cazzola R and Cestaro B: Studies on the antioxidant activity of milk caseins. Int J Food Sci Nutr 50: 291-296, 1999. 